\title{
La política ambiental en Colombia: logros obtenidos y problemas a superar
}

\author{
Environmental policy in Colombia: achievements obtained and problems \\ to be overcome
}

\begin{abstract}
RESUMEN
El medioambiente se consagró en la Constitución de 1991 como un derecho cuya protección debe garantizar el Estado. Para lo cual se crearon una serie de entidades, entre ellas el Ministerio de Medio Ambiente -hoy Ministerio de Ambiente-, las CAR y otras, encargadas de velar por su protección y ser las máximas autoridades en materia de trámites administrativos ambientales. Se acuñó así el término desarrollo sostenible y se creó un discurso proteccionista que se ha visto rebasado por la realidad donde el hecho de no reglamentarse muchos procedimientos, no contar con recursos humanos y operativos para investigar y controlar la explotación del medioambiente, hacen necesario un replanteamiento de sus políticas de protección por medio de mecanismos expeditos que lo posibiliten, donde se incentive la participación de los ciudadanos a través de las acciones jurídicas existentes y la formulación de propuestas encauzadas a este fin.
\end{abstract}

PALABRAS CLAVE

Medio Ambiente, Protección, Explotación, Desarrollo, Políticas, Mecanismos, Participación.

\section{ABSTRACT}

The environment was issued in the 1991 Constitution as a right whose protection the State must guarantee. To this end, a number of entities were created, including the Ministry of the Environment -now the Ministry of the Environment- CAR and others, charged with ensuring their protection and being the highest authorities in matters of environmental administrative procedures. The term "sustainable development" was thus coined and a protectionist discourse was created which has been overtaken by the reality where the failure to regulate many procedures, lack of the human and operational resources to investigate and control the exploitation of the environment, rethinking the policies of protection of the same by means of expeditious mechanisms that make it possible, where the participation of citizens is encouraged through existing legal actions and the formulation of proposals directed to this end.

\section{KEYWORDS}

Environment, Protection, Exploitation, Development, Policies, Mechanisms, Participation.

\section{ABELARDO LEAL HERNÁNDEZ}

Docente-investigador de la Universidad Manuela Beltrán. Magíster en Derechos Fundamentales y Poderes Públicos de la Universidad de Salamanca. Candidato a Doctor en Derecho de la Universidad de Salamanca.

\section{LUIS EDUARDO SERRANO RINCÓN}

Abogado de la Universidad Nacional. Especialista en Instituciones Jurídico-Procesales. Candidato a magister en Filosofía del Derecho y Teoría Jurídica de la Universidad Libre. Miembro del grupo de investigación Derecho, Justicia y Desarrollo Global de la Universidad Manuela Beltrán.

Correo: luis.serrano@umb.edu.co

Recibido: 11 de febrero de 2015 • Aceptado: 27 de julio de 2015 


\section{INTRODUCCIÓN}

El presente artículo busca hacer un acercamiento a los logros alcanzados en materia ambiental desde la expedición de la Constitución de 1991 hasta la actualidad, para lo cual refiere brevemente qué vacíos existían anteriormente y mostrar los avances en materia de protección del medioambiente.

Partiendo de los artículos constitucionales que precisamente establecen el derecho a medioambiente, y lo prevén como un derecho de carácter colectivo, porque pertenece a la comunidad o sociedad en general, se pasa a estudiar las leyes que se han expedido para crear las autoridades o entidades, competencias, facultades, procedimientos demás en materia ambiental.

Asimismo, se estudiarán las reglamentaciones a dichas leyes, cuándo han sido expedidas, ya que en esta materia existen vacíos procedimentales que, como se verá, afectan la protección del medioambiente.

A lo largo del texto, se buscará dilucidar el problema de que si bien existe un discur-

so jurídico en materia de medioambiente no conlleva necesariamente su protección pues la realidad refleja otro matiz y es que la explotación económica del territorio y sus recursos, los intereses particulares y la poca eficiencia del Estado en su control, representan grandes óbices para el pleno disfrute de este derecho para lo cual se deben pensar, identificar y aplicar medidas tendientes asegurar su protección.
I. El derecho al medioambiente en la constitución de 1991: logros y problemas sobrevinientes

La protección del medioambiente se fortaleció con la consagración en la Constitución de 1991 de principios tendientes a su conservación. Así, el capítulo 3 de la referida Constitución trata de Los Derechos Colectivos y del Medio Ambiente, estableciendo el derecho de todos los ciudadanos a gozar de un medioambiente sano, como también su participación en las decisiones que puedan afectarlo.

Igualmente, se estableció que estará a cargo del Estado la planificación de los recursos naturales, su conservación y restauración asegurando un desarrollo sostenible, como lo dicta el artículo 80 de dicha Norma fundamental, así como la prevención del riesgo deterioro ambiental, la exigencia de la reparación de los daños causados a quienes los generen y la imposición de sanciones legales.

Asimismo, se prohíbe la fabricación e importación de armas químicas, biológicas y nucleares, así como también residuos de esta índole. Además, se estableció que el Estado tiene el deber de proteger el medioambiente y velar por la conservación y restauración espacio público.

Estas consagraciones han facilitado la protección efectiva del medioambiente, la cua ra apremiante debido a que, con el cambio de concentración poblacional y productiva del campo a la ciudad, se ha generado mayor contaminación y deterioro del medioambiente sobre todo a partir de los años 50; así, como lo afirma Rodríguez Becerra:

"el crecimiento poblacional ha sido uno de los detonantes de la degradación de ambiente. Pero este fenómeno se teje en una compleja trama de causas próximas y mediatas, entre las cuales se mencionan los patrones de consumo y producción predominantes, los patrones del comercio internacional y las amenazas ambientales globales" (Rodríguez Becerra, 1998, p.304).

Al aumentar la contaminación derivada de crecimiento poblacional, del surgimiento de fábricas e industrias, se hizo necesaria la creación de entidades tendientes a velar por protección del medioambiente, por la gran cantidad de desechos industriales, la contaminación de quebradas y ríos que coadyuvan a la escasez del agua potable, además de destruir ecosistemas.

Sin embargo, debe anotarse que el medioam biente, pese a estas consagraciones de carácter constitucional, en Colombia como en otros países, como el espacio europeo, no ha sido consagrado literalmente como un derecho fundamental, $y$ en principio no goza de las acciones que per se llevan ínsitos estos derechos: "Siendo deseable la configuración del medioambiente como un derecho fundamental y no como un simple principio [...]" (Figuruelo Burrieza, 2005, p.29)
No obstante lo anterior, la Corte Constitucional en Sentencia No. T-536/92, ha expresado:

“El ambiente sano y ecológicamente equilibrado es un derecho constitucional fundamental, pues su violación atenta directamente contra la perpetuación de la especie humana $y$, en consecuencia, con el derecho más fundamental del hombre: la vida. El derecho a la salud y a la vida son derechos fundamentales porque son esenciales al hombre, la salud se encuentra ligada al medioambiente que le rodea y que dependiendo de las condiciones que éste le ofrezca, le permitirá desarrollarse económica y socialmente a los pueblos, garantizándoles su supervivencia. Existen unos límites tolerables de contaminación que al ser traspasados constituyen un perjuicio para el medioambiente y la vida, que no pueden ser justificables y por lo tanto exigen imponer unos correctivos".

Por otra parte, si bien la Constitución estableció la protección al medioambiente a cargo del Estado, la Ley 99 de 1993 supuso el marco legal para implementarla y ejercerla, pues creó el Ministerio del Medio Ambiente como entidad máxima encargada de formular políticas públicas en materia ambiental, gestionarlas, así como ejercer vigilancia y control dirigidos a la conservación y protección del medioambiente en el ámbito nacio-

Asimismo, se crearon institutos de investigación para apoyar sus labores en el plano técnico y científico. 
Igualmente, se crearon las CAR, dentro del materia ambiental, han posibilitado la formarco de la descentralización de la gestión mulación de políticas públicas tendientes ambiental; las CAR son la "máxima autoridad proteger y restaurar el medioambiente; así:

ambiental regional, que son, a la vez, autónomas frente al Ministerio del Medio Ambiente y a las entidades territoriales (departamentos y municipios)" (Rodríguez Becerra, 2003, p.41).

La autonomía de las CAR ha hecho posible que se adelanten políticas de protección de medioambiente:

"la relativa independencia de las CAR frente a los entes territoriales, así como la ortaleza técnica de algunas de ellas, son dos hechos que explicarían por qué en Colombia se han podido poner en marcha instrumentos de gestión de cierta complejidad, como las tasas retributivas por vertimientos en los cuerpos de agua, en contraste con la casi totalidad de los países de Latinoamérica y en general de gran parte de los países en desarrollo), en los cuales ello no ha sido posible, en virtud de la poca autonomía o debilidad de sus autoridades ambientales regionales (...). En forma similar, como resultado de esta capacidad, las CAR han ejecutado proyectos de cierto alcance, como lo ilustra la reforestación protectora de las cuencas hidrográficas que surten a los acueductos municipales, que en el periodo 1994-2002 ascendió a 150.000 hectáreas" (Rodríguez Becerra, 2003, p.42).

Ahora bien, la creación del Ministerio del Medio Ambiente y la descentralización en Ambiente, el IDEAM, del Instituto de Inves- tigaciones del Pacífico, el Instituto de Investigaciones Marinas -invemar-, y el Instituto Alejandro Von Humboldt. Esto permite conocer más nuestro medioambiente, y con ello tener conocimiento de su vulnerabilidad y las formas para prevenir posibles peligros ambientales o de restaurar ecosistemas, bosques o trabajar en la descontaminación de ríos, que, como el Bogotá, han sido contaminados por desechos químicos y residuos que la población arroja en él.

Otro factor importante para el avance en materia de políticas públicas para proteger medioambiente, ha sido la destinación de mayores recursos para estos fines, que fueron consagrados en la Constitución Política de 1991, y que provienen de quienes causan daño al medioambiente, y en consecuencia deben repararlo, como de la Nación y las entidades territoriales:

"La mayor cantidad de recursos económicos hoy disponibles para la inversión ambiental es una consecuencia de los mecanismos que, para su financiación, se previeron en la Constitución de 1991 y en la ley de creación del Ministerio del Medio Ambiente. Entre ellos se mencionan e porcentaje al impuesto predial destinado a las corporaciones autónomas regionales, las transferencias del sector eléctrico a las CAR y a los municipios, el Fondo de Regalías que financia proyectos ambientales $\mathrm{d}$ las entidades territoriales y la tasa retributiva por descargas contaminantes a las guas. Estos, más otros mecanismos previstos en la ley, ubican a Colombia como el país de América Latina y el Caribe que cuenta con el más completo sistema de instrumentos para la generación de recursos económicos para la gestión ambiental. Son instrumentos cuya existencia se basa en los principios del que contamina paga $y$ el que usa los recursos naturales paga, y que constituyen una de las mayores fortalezas del sistema ambiental colombiano. Sin embargo, los recursos producidos por estos instrumentos se encuentran concentrados en ocho corporaciones, lo cual significa que las veinticinco restantes dependen de las rentas generales de la Nación, una debilidad del sistema, que requiere medidas para ser corregida" (Rodríguez Becerra, 2003, p.42).

El trabajo del Ministerio del Medio Ambiente, de las CARS y demás organismos protectores del medioambiente, han producido políticas públicas para su conservación y restauración, teniendo como resultado la descontaminación de muchos ríos y quebradas, la disminución de la contaminación emanada de industrias, empresas, servicios públicos, y obras de infraestructura en construcción. Igualmente, se ha conseguido disminuir la contaminación del aire, con programas de control de su calidad en varias ciudades, y con la chatarrización de buses obsoletos, el uso de filtros en los vehículos, y el reemplazo de la gasolina por el gas natural en otros casos. También se ha trabajado en la recuperación de humedales en Bogotá, y de otros ecosistemas como bosques y ciénagas. Además, se ha conseguido disminuir la contaminación visual quitando vallas publicitarias en 
Bogotá, entre otras medidas. Así mismo la reforestación ha sido un logro importante de estas políticas, junto con el mayor cuidado que se le ha puesto a los parques naturales nacionales y al aumento de sus áreas.

De la misma forma, se ha fortalecido la educación ambiental en escuelas, colegios y universidades y se ha promovido por medios masivos de comunicación para generar conciencia en la población de la necesidad de proteger el medioambiente y no contaminarlo. También ha sido importante la tarea realizada por las entidades territoriales en centro urbanos, como la arborización, el aumento de las zonas recreativas o verdes, la creación de nuevos sistemas de transporte que disminuyen la contaminación, como las ciclovías.

Igualmente las medidas tomadas para mitigar el cambio climático han sido relevantes.

De igual importancia han sido los programas públicos para promover el reciclaje, y con ello disminuir la contaminación urbana. Las tareas adelantadas para la recolección adecuada de basuras y la prohibición de contaminar áreas verdes y públicas con ellas, ha favorecido la conservación del medioambiente urbano.

En cuanto a la reducción de la contaminación del agua causada por las industrias manufactureras, entre otras, y por el hecho de arrojar basuras a los cauces de los ríos y quebradas, es importante afirmar que:
“En diez años, la contaminación del agua, pasó de ser el problema ambiental más importante del sector, con graves consecuencias para las regiones en las cuales se ubican las plantas extractoras, a constituirse en un asunto irrelevante, cuando antes de 1993 se caracterizaba por sus altos niveles de vertimientos de carga orgá nica a las aguas.

"Actualmente, el $98 \%$ de las cincuenta plantas extractoras cuentan con sistemas de tratamiento de vertimientos, que re mueven más del $95 \%$ de la carga orgánica del caudal vertido. De esta manera, todas las empresas del sector cumplen con la normatividad vigente. Además, cerca de la mitad utiliza las aguas tratadas para el riesgo de las plantaciones, con lo cual se prevé que este sector llegará a un vertimiento cero en el mediano plazo.

"En general, el mejor desempeño ambiental de la industria es, en gran parte, el resultado de la puesta en marcha de nuevas políticas e instrumentos de polítca, así como del fortalecimiento de otras que se venían utilizando de tiempo atrás. Entre las primeras, se destacan los Convenios Voluntarios de Concertación para la Producción Limpia, los programas de asistencia técnica y los instrumentos económicos; y entre los segundos, sobresale las licencias ambientales, la educación y la información (Rodríguez Becerra, 2003, pp.44-45).

De la misma manera, ha sido sumamente im- portante la creación y protección de parques naturales, integrándolos en el Sistema Nacional de Áreas Protegidas. Esto ha posibilitado que estas áreas, donde se desarrollan ecosistemas y constituyen fuente de aire puro, no sean destinadas a la construcción de centros turísticos.

Campañas encaminadas a prohibir la explotación ilegal de los recursos naturales, y la comercialización de fauna y flora silvestres, han sido relevantes para proteger el medioambiente y conservarlo.

gualmente, la Constitución Política de 1991 ha establecido instrumentos jurídicos para que la sociedad pueda ser activa en la defensa y protección del medioambiente, consagrando la acción de tutela y las acciones populares y de grupo como mecanismos para hacer efectiva esta protección.

Otro factor importante es que a la luz de la Ley 99 de 1993 se creó el Consejo Naciona Ambiental y el Consejo Técnico Asesor de Política y Normatividad Ambiental, buscando incentivar la participación de la sociedad civil en la reglamentación de las disposiciones y políticas ambientales, es por ello que: "Co la Ley 99 de 1993 se busca involucrar a la sociedad civil en general y al sector privado en la solución de los problemas ambientales" (Sánchez Pérez, 2002, p.94).

Leyes posteriores, como la 52 de 1994 y 188 de 1995, suponen marcos jurídicos tendientes a ponderar el desarrollo económico frente a los riesgos que implique para el Por lo cual si bien, como lo afirma el mismo

medioambiente, lo cual al aplicarse con sano juicio puede llevar a producir resultados favorables para este.

No obstante, la gestión del Estado en política ambiental ha estado limitada por la aplicación de modelos neoliberales que han impedido encauzar las políticas a su verdadera y última finalidad, como es la protección del medioambiente para beneficio común, y no el favorecimiento de ciertos sectores minoritarios, como lo afirma el académico Ernesto Guhl en entrevista con la revistas Semana:

“Ernesto Guhl: Hay varias razones, pero en mi concepto la principal es que existen muchas contradicciones entre el desarroIlo extractivista y la política ambiental del país. Como fue planteado en la ley, el desarrollo sostenible necesita de un Estado fuerte que cuide y garantice los derechos de la población de hacer uso de un bien público que es el medioambiente. Sin embargo, lo que hemos visto es una progresiva "privatización" de la gestión ambiental en favor de las iniciativas empresariales. Eso es notorio, por ejemplo, con las reformas al proceso de licenciamiento para que sea más rápido y menos riguroso cuando se trata de proyectos que se suponen de interés estratégico como la infraestructura o la minería. En otras palabras, la política ambiental no es autónoma sino que cada día se transforma para adaptarse a los mandatos del modelo neoliberal" (Guhl, 2015).

REVISTA VIS IURIS I No.3, Vol. 21 57-67| Enero-Junio, 2015 I Universidad Sergio Atroledal Escuela de Dereccho I Seccional Santa Marta, Sede Centro 
Guhl, las políticas en materia ambiental en Fenómenos como la fumigación de cultiColombia son avanzadas, se requiere ponerlas en práctica dejando a un lado el modelo neoliberal y centrándose prioritariamente en la protección del medioambiente por encima de intereses particulares.

\section{CONCLUSIONES}

La Constitución Política de 1991 estableció principios y mecanismos para la protección del medioambiente por parte del Estado $y$ la sociedad. Asimismo, en virtud de ellas se crearon nuevas entidades para su defensa $y$ nuevas formas de financiamiento para ejecutar sus labores, que aumentaron los ingresos y el presupuesto en esta materia. Estas consagraciones hicieron posible adelantar políticas públicas serias encaminadas a la conservación del medioambiente, tanto urbano como rural. Como fruto de ello, se ha logrado la disminución de la contaminación de fuentes de agua dulce, del aire en ciudades principales, así como la reforestación rural y arborización urbana, y el aumento en las áreas de los parques naturales.

No obstante, todavía deben adelantarse más políticas públicas orientadas a proteger el medioambiente, pues este se encuentra constantemente amenazado por construcción urbana, el ruido, la sustitución de zonas rurales por centros turísticos o comerciales, el surgimiento de nuevas industrias o la falta de control sobre estas, la sequía de ríos y quebradas y su contaminación mediante basuras o residuos, así como la explotación ilegal de madera y otros recursos naturales. vos ilícitos, que afectan zonas verdes con importantes ecosistemas, así como el desplazamiento de población rural a centros urbanos, con el consecuente hacinamiento surgimiento de enfermedades, insatisfacción de las necesidades básicas de agua potable y alimentación, deben ser objeto, como los anteriores problemas, de programas serios

tendientes a disminuir su impacto o superar-

con las políticas públicas del Ministerio de

Medio Ambiente, las CAR y las entidades territoriales, sino también de la sociedad, en e sentido de que tome conciencia de la necesidad de no contaminar el medioambiente con sus acciones o de no ser parte activa en ellas, de ayudar a restaurarlo o prevenir su deterioro, mediante la denuncia pública y la realización de acciones u omisiones, como no arrojar basura a la calle ni a las fuentes de agua, como tampoco en las zonas rurales, usar filtros en los vehículos o cambiarse otras formas de combustible como el gas natural, y reciclar las basuras que otros arrojen o promover esta campaña.

Otro punto importante es la prevención de los deterioros al medioambiente; son frecuentes en el ámbito nacional fenómenos como los incendios forestales que muchas veces terminan acabando con ecosistemas enteros. Por ello, deben establecerse sistemas de prevención que comiencen por programas educativos en escuelas, colegios y universidades, así como difundirlos por medios masivos de comunicación (volantes, radio, televisión, periódicos), el aumento del lo de raíz. Para ello, se debe contar, no solo número de guardabosques equipados de equipos de comunicación eficientes para in formar cualquier hecho de estos, y capaces de velar por el cuidado de estas zonas, y el colateral aumento de bomberos voluntarios oficiales, así como Defensa Civil, dotándolos de equipos modernos y eficaces para enfrentar estos fenómenos.

Un punto de igual o mayor relevancia es la expansión de las ciudades ante el crecimiento poblacional. Esta expansión debe organizarse detenidamente procurando no afectar ecosistemas aledaños, ni tocar fuentes de agua o zonas forestales de gran valor, puesto que:

"La conurbación y otras modalidades de urbanización que se han implantado sin ningún tipo de ordenamiento generan impactos a todo nivel. El crecimiento de las ciudades hacia ecosistemas de gran riqueza ambiental, como los humedales y los bosques primarios y secundarios, produce mayor deterioro ambiental y presión adicional sobre los ecosistemas" (Contralorí General de la República, 2001, p.236).

De esta misma manera, deben tomarse políticas dirigidas al uso adecuado del suelo, eniendo en cuenta los ecosistemas que se perjudican y la población humana que habita en ellos, como es el caso de la explotación de hidrocarburos en zonas indígenas. Debe primar, más que el interés económico de moo la presión de gobiernos o compañ́as internacionales, los derechos de la po- blación y de la sociedad a un medioambiente sano que no ponga en riesgo su existencia. Así mismo debe evitarse la erosión mediante programas pedagógicos serios y de acción estatal y social, igualmente generando la explotación y cuidado de zonas fértiles para la agricultura, estableciendo sistemas de riego para ellas y evitar de esta forma su sedimentación. También se deben otorgar terrenos baldíos con estos fines que redundan en la generación de empleo y alimentos para la población. La creación de bancos de datos sobre uso del suelo, sus principales problemas y riesgos, así como las soluciones y medidas a tomar es de suma importancia, puesto que:

"el país no posee registros actualizados sobre el uso de la tierra, y, en consecuencia, enfrenta serias dificultades para asumir una política adecuada de manejo del recurso suelo, tanto a nivel productivo como de ordenamiento territorial y de reforma agraria. En términos ideales, el país debiera actualizar sus mapas nacionales de uso del suelo por lo menos cada tres años, o cada cinco, en el peor de los casos" (Contraloría General de la República, 2001)

En el caso del desplazamiento, la solución idónea sería el fin del conflicto armado, pero mientras tanto pueden adoptarse medidas como la realización de brigadas gratuitas de salud para ellos y su reubicación en otras zonas o viviendas donde sean menos vulnerables a las enfermedades y estén menos hacinados. Además, es necesario crear progra- 
mas de empleo para esta población, y para Ley 99 de 1993. Ley General Ambiental de toda aquella que no puede satisfacer sus Colombia.

necesidades básicas, puesto que el bienestar

social también debe ser una política pública

que contribuya a conservar el medioambien-

te urbano y rural, ya que los seres humanos,

después de todo, hacen parte de él.

Del medioambiente se deriva el aire que res-

piramos, los alimentos que consumimos, el

agua que tomamos, y constituye el espacio

donde vivimos -rural o urbano-. Por ello, es deber de todos protegerlo y ayudar en las políticas públicas que el Estado, a nivel nacional o regional, formula y desarrolla, y que estas se ejecuten persiguiendo fines comunes por encima de intereses empresariales o económicos, puesto que si se pone en una balanza el medioambiente frente a derechos como el de empresa, propiedad privada, etc., sin duda debe prevalecer la protección al primero.

Por último, el convertir el derecho al medioambiente como de rango fundamen-

tal, no por vía de la jurisprudencia constitucional, sino como consagración en el mismo texto constitucional, permitiría darle el valor que entraña y que los ciudadanos puedan directamente ejercer las acciones que de ello deriva.

Ley 52 de 1994.

Ley 188 de 1995

Sentencia No. T-536/92.

Libros y artículos

Alcaldía de Bogotá (2004). Impacto Social del Programa Distrital de Medio Ambiente. Bogotá: Ed. Alcaldía de Bogotá.

Contraloría General de la República (2001). Estado de los Recursos Naturales y del Ambiente, Colombia 2000-2001, Políticas, Suelos, Mares y Costas. Bogotá: Ed. Contraloría General de la República.

Figuruelo Burrieza, Á. (2005). Protección constitucional del medioambiente en España y Europa. Criterio Jurídico, 5

Manga Certain, J. y otros (2005). Guía de Gestión Ambiental Urbana. Barranquilla: Ediciones Uninorte.

Moreno Molina, J. A. (1998). La protección ambiental de los bosques. Madrid: Ed. Marcial Pons.

\section{REFERENCIAS}

Normatividad

Constitución Política de 1991 (2000). Bogotá: Ed. Legis.
Rodríguez Becerra, M. (1998). La Reforma ambiental en Colombia. Bogotá: Ed. TM.

Rodríguez Becerra, M. (2003). Política Pública y Medio Ambiente en Colombia, Economía

\section{Colombiana. Revista de la Contraloría Gene- Entrevistas}

\section{ral de la República.}

Sánchez Pérez, G. (2002). Desarrollo y medio ambiente: una mirada a Colombia. En Economía y Desarrollo. Bogotá: Fundación Universidad Autónoma.

Entrevista a Ernesto Guhl, accesible en Guhl, en http://sostenibilidad.semana.com/medio-ambiente/articulo/ernesto-guhl-la-politica-ambiental-de-colombia-es-avanzadael-problema-es-que-no-se-pone-en-practi$\mathrm{ca} / 34351$ 